\title{
DESIGNING MOBILE INQUIRY-BASED LEARNING ACTIVITIES: LEARNERS' AGENCY AND TECHNOLOGICAL AFFORDANCES
}

\author{
Esther Tan ${ }^{1}$, Christian Glahn ${ }^{2}$ and Marcus Specht ${ }^{3}$ \\ ${ }^{l}$ Dr., Researcher \\ ${ }^{2}$ Prof. Dr., Research Fellow \\ ${ }^{3}$ Prof. Dr., Scientific Director \\ Leiden-Delft-Erasmus, Centre for Education and Learning (LDE-CEL), Delft University of Technology, Netherlands
}

\begin{abstract}
Recent discourse and research studies on mobile learning showed increasing awareness of the complexity of mobile learning in the digital age. Notwithstanding mobile devices, Web 2.0 and Web 3.0 technologies have greatly empowered learners and educators to overcome the constraints of conventional education, such as time, space, location and to learn on the move. However, balancing technological dependency and learner autonomy remains an area of contention in designing meaningful mobile learning activities. Hence, this interactive and participatory workshop aims to bring together researchers and practitioners working on this issue to share their experience and to engage in facilitated activities and discussions on designing mobile learning activities that effectively balance learners' agency with mobile technology. Additionally, this workshop also provides a platform for unsolved challenges and future research directions on smart technology and smart learning spaces in the context of mobile learning, laying the groundwork for joint research efforts.
\end{abstract}

\section{Plenary session (45 min)}

Part I: Discussion on the design challenges and issues pertaining to mobile learning in the era of digital mobility. This integrates perspectives on mobility of learners, smart technologies and learner agency, bridging formal and informal learning spaces, outdoor enclosed and open spaces.

Part II: Using the six-dimension analytical framework (Appendix 1), learners' agency and technology support in the following categories of mobile learning activities (Appendix 2) will be discussed:

- Direct instruction: location guidance, procedural guidance and metacognitive guidance

- Content: fixed and dynamic

- Data collection: cooperative and collaborative

- Peer-to-peer interactions: social asynchronous and social synchronous

- Contextual support: augmented, immersive and adaptive feedback

\section{Hands-on session (1hr)}

Participants will work in small groups on designing mobile inquiry-based learning scenarios in their respective education institutional contexts.

Following is a checklist to guide your mobile learning design:

1. Target group - for whom is the mobile inquiry-based learning scenario intended?

2. Learning objectives - what do you want the students to learn and experience?

3. Content - What type of content will the students be confronted with and the (technological) support required to facilitate learning and promote learner agency? 
4. Context - where do students learn this? what are essential elements in the (formal and informal) contexts needed to achieve the learning objectives? What are relations to practices beyond the curriculum?

5. Learning activities and phasing - what do students do? How do the learning activities (in the different (formal and informal) contexts relate to each other? E.g., where do you start (or school or at ...), what follows?

6. Didactics: Starting points - what type of learning process (e.g, inquiry-based learning, self-regulation, feedback and reflection) do you want to support?

7. Didactics: Control - What is the responsibility for the learning process?

8. Didactics: Guidance - What (pedagogical) support do students receive? from what or from whom?

9. Peer-to-peer interactions: What forms of interaction (synchronous/ asynchronous) will engender learning in your activity design?

10. Contextual support (Tools and technological) - What is the role of technology in the learning and support process?

11. Evaluation and assessment - when is your design successful? what should the result be? how do you determine that?

\section{Materials (will be provided)}

- Analytical framework \& tools

- Design template

\section{Concluding session (45 min)}

Gallery walk and presentation of mobile inquiry-based lesson designs, followed by a concluding discussion about issues arising and directions for future work in the mobile learning: smart technologies, smart data and smart learning spaces.

\section{REFERENCES}

Gikas, J., \& Grant, M. M. (2013). Mobile computing devices in higher education: Student perspectives on learning with cellphones, smartphones \& social media. The Internet and Higher Education, 19, 18-26.

Glahn, C., \& Gruber, M.R. (2018). Learning design for teachers in a hurry. In Proceedings of the Online Educa Berlin. Berlin, Germany, December 6, 2018.

Rusman, E., Tan, E., \& Firssova, O. (2018). Dreams, realism and critics of stakeholders on implementing Seamless Learning Scenario's in Dutch Secondary education. In D. Parsons, R. Power, A. Palalas, H. Hambrock \& K. MacCallum (Eds.), Proceedings of 17th World Conference on Mobile and Contextual Learning (pp. 88-96). Concordia University Chicago, Chicago, IL, USA. Retrieved November 30, 2018 from https://www.learntechlib.org/p/184927/.

Suárez, Á., Specht, M., Prinsen, F., Kalz, M., \& Ternier, S. (2018). A review of the types of mobile activities in mobile inquiry-based learning. Computers \& Education, 118, 38-55.

Tan, E., Rusman, E., Firssova, O., Ternier, S., Specht, M., Klemke, R., \& So, H.J. (2018). Mobile Inquiry-based Learning: Relationship among levels of inquiry, learners' autonomy and environmental interaction. In D. Parsons, R. Power, A. Palalas, H. Hambrock \& K. MacCallum (Eds.), Proceedings of 17th World Conference on Mobile and Contextual Learning (pp. 22-29). Concordia University Chicago, Chicago, IL, USA. Retrieved November 30, 2018 from https://www.learntechlib.org/p/184919/. 


\section{APPENDIX 1}

The 12 types of mobile activities based on the six-dimension analytical framework (Suárez, Specht, Prinsen, Kalz, \& Ternier (2018).

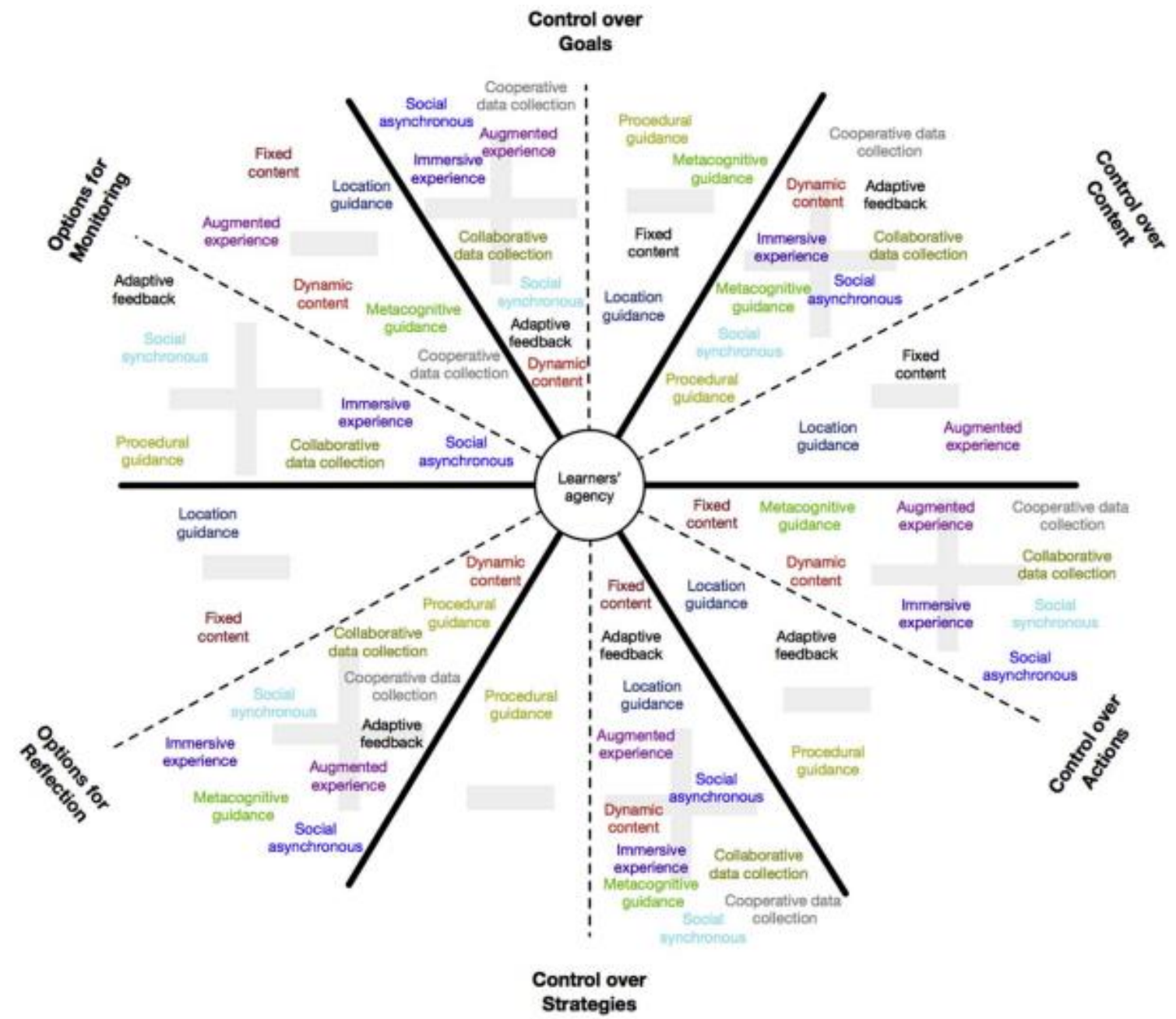

\section{APPENDIX 2}

Technological support for mobile inquiry-based learning and learner agency (Suárez, Specht, Prinsen, Kalz, \& Ternier (2018).

Table 1. Contextualized Guidance and Instruction

\begin{tabular}{ll}
\hline Direct instruction & Technological affordances \\
\hline Location guidance & $\begin{array}{l}\text { GPS, Radio Frequency Identification (RFID), Quick Response Codes (QR } \\
\text { codes), Personal Digital Assistants } \\
\text { (PDAs) \& Geocaches }\end{array}$ \\
\hline Procedural guidance & $\begin{array}{l}\text { Task/process execution, question-guided tours, process or collaboration } \\
\text { scripts }\end{array}$ \\
\hline Metacognitive support & $\begin{array}{l}\text { Mental model construction, carry out interpretations, scaffolding to } \\
\text { understand scientific concepts, reducing } \\
\text { cognitive load in data collection \& interpretation processes. }\end{array}$ \\
\hline
\end{tabular}


Table 2. Access to Content

\begin{tabular}{ll}
\hline Access to content & Technological affordances \\
\hline Fixed content & Local repositories, preloaded e-libraries, preloaded mobile apps, RFID tags, \\
& QR codes, Geocaches and digital artifacts \\
& triggered with GPS and AR \\
\hline Dynamic content & Browsing, filtering, interpreting information found on the web, remote \\
& databases, concept maps, discussion forums, \\
& KWL (What do I know/ wonder/ learn) tables, online blogging, wikis and \\
social networks.
\end{tabular}

Table 3. Data Collection

\begin{tabular}{ll}
\hline Data collection & Technological affordances \\
\hline Cooperative & $\begin{array}{l}\text { Capturing multimedia data, taking notes, drawing schemas, multiple choice } \\
\text { questions to guide data collection and } \\
\text { collect information for KWL tables. }\end{array}$ \\
\hline Collaborative & $\begin{array}{l}\text { Collaborative concept maps and graphical data visualization of data jointly } \\
\text { collected. }\end{array}$ \\
\hline
\end{tabular}

Table 4. Peer-to-peer interaction

\begin{tabular}{ll}
\hline Peer-to-peer interaction & Technological affordances \\
\hline Synchronous & Instant messaging, chats with notifications. \\
\hline Asynchronous & $\begin{array}{l}\text { Forums, online discussion panels, online platforms without notifications and } \\
\text { social boards. }\end{array}$ \\
\hline
\end{tabular}

Table 5. Contextualized support

\begin{tabular}{ll}
\hline Direct instruction & Technological affordances \\
\hline Augmented experience & GPS, timer or accelerometer \\
\hline Immersive experience & $\begin{array}{l}\text { GPS, big display for immersive simulation, stargazing simulation, 3D } \\
\text { weather simulation. }\end{array}$ \\
\hline Adaptive feedback & intelligent systems that give hint for making further observations \\
\hline
\end{tabular}

